\title{
Effects of climatic warming on spring phenology in subtropical trees: process-based modelling with experiments designed for model development
}

\author{
Rui Zhang ${ }^{1}$, Jianhong Lin $^{2}$, Fucheng Wang ${ }^{2}$, Heikki Hanninen ${ }^{1}$, and Jiasheng $\mathrm{Wu}^{2}$ \\ ${ }^{1}$ Zhejiang A and F University \\ ${ }^{2}$ Zhejiang A\&F University
}

January 31, 2021

\begin{abstract}
We developed process-based tree phenology models for four subtropical tree species, and for the first time for these trees, we based the model development on explicit experimental work particularly designed to address the processes being modelled. For all the four species, a model of seedling leafout was developed, and for Torreya grandis, a model for female flowering in adult trees was additionally developed. The models generally showed reasonable accuracy when tested against two sources of independent data. In scenario simulations, the models projected an advanced spring phenology under climatic warming for 2020 - 2100. For the leafout of seedlings, the advancing rates varied between 4.7 and 5.9 days per one ${ }^{\circ} \mathrm{C}$ warming, with no major differences found between the climatic scenarios RCP4.5 and RCP8.5. For Torreya flowering, less advancing was projected, and the projected advancing per one ${ }^{\circ} \mathrm{C}$ warming was less for RCP8.5 (0.9 days / $\left.{ }^{\circ} \mathrm{C}\right)$ than for $\mathrm{RCP} 4.5$ (2.3 days $\left./{ }^{\circ} \mathrm{C}\right)$. The low advancing rates of Torreya flowering were caused by reduced chilling under the warming climate and by the particular temperature responses found for Torreya flowering. These findings highlight the need to base the model development on explicit experiments particularly designed to address the process modelled.
\end{abstract}

\section{Hosted file}

zhang et al - manuscript.pdf available at https://authorea.com/users/392868/articles/506629effects-of-climatic-warming-on-spring-phenology-in-subtropical-trees-process-basedmodelling-with-experiments-designed-for-model-development 


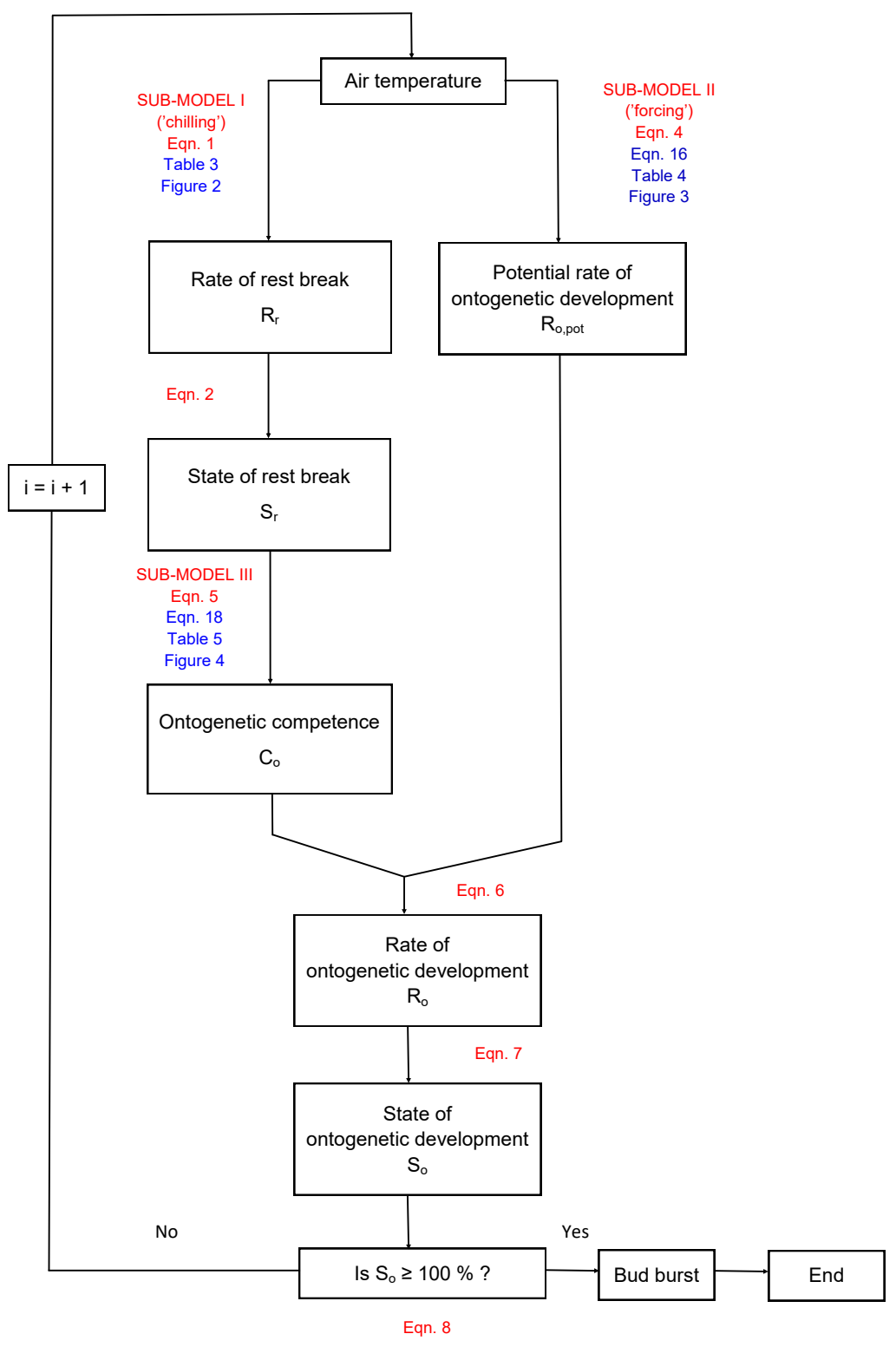



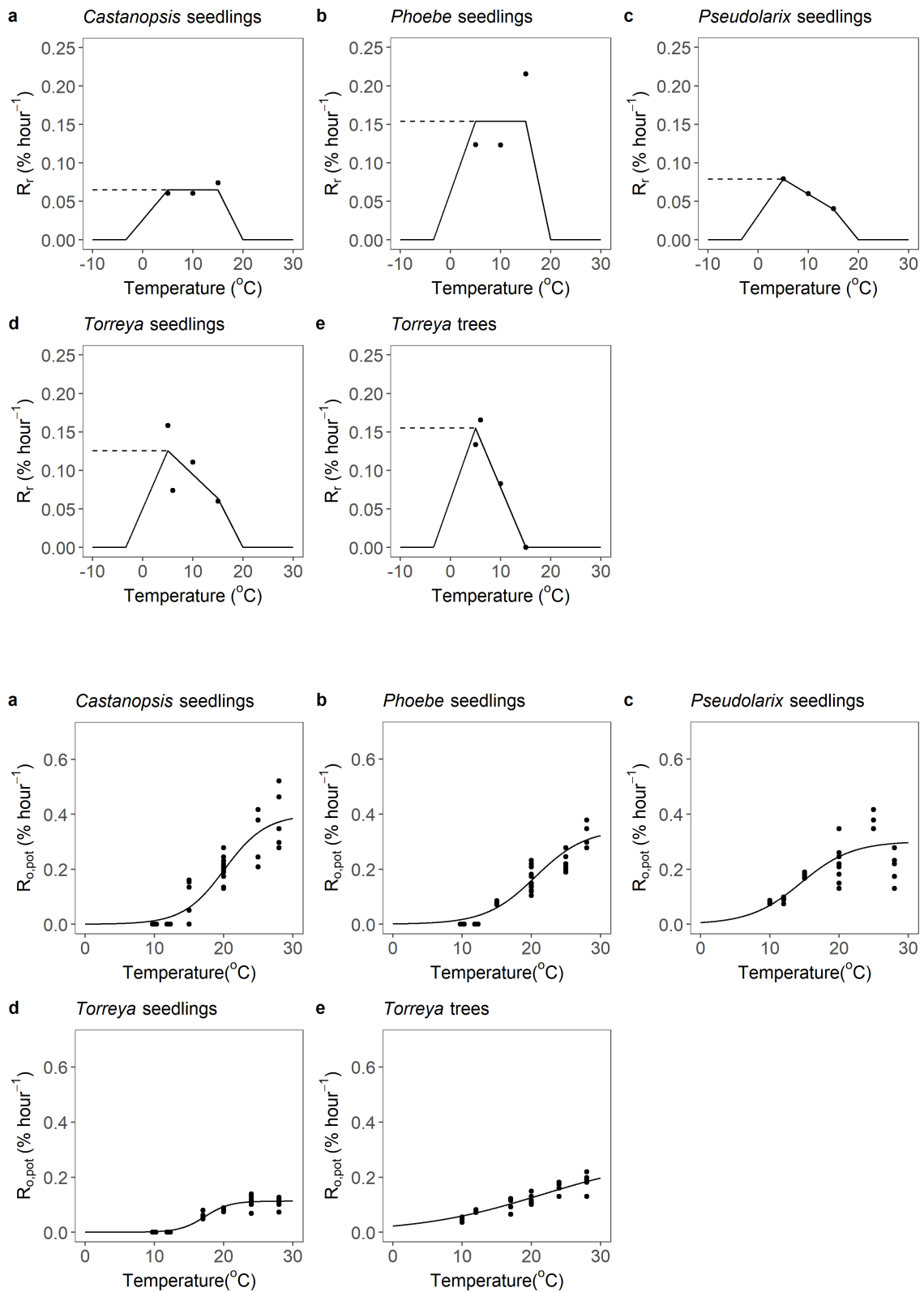

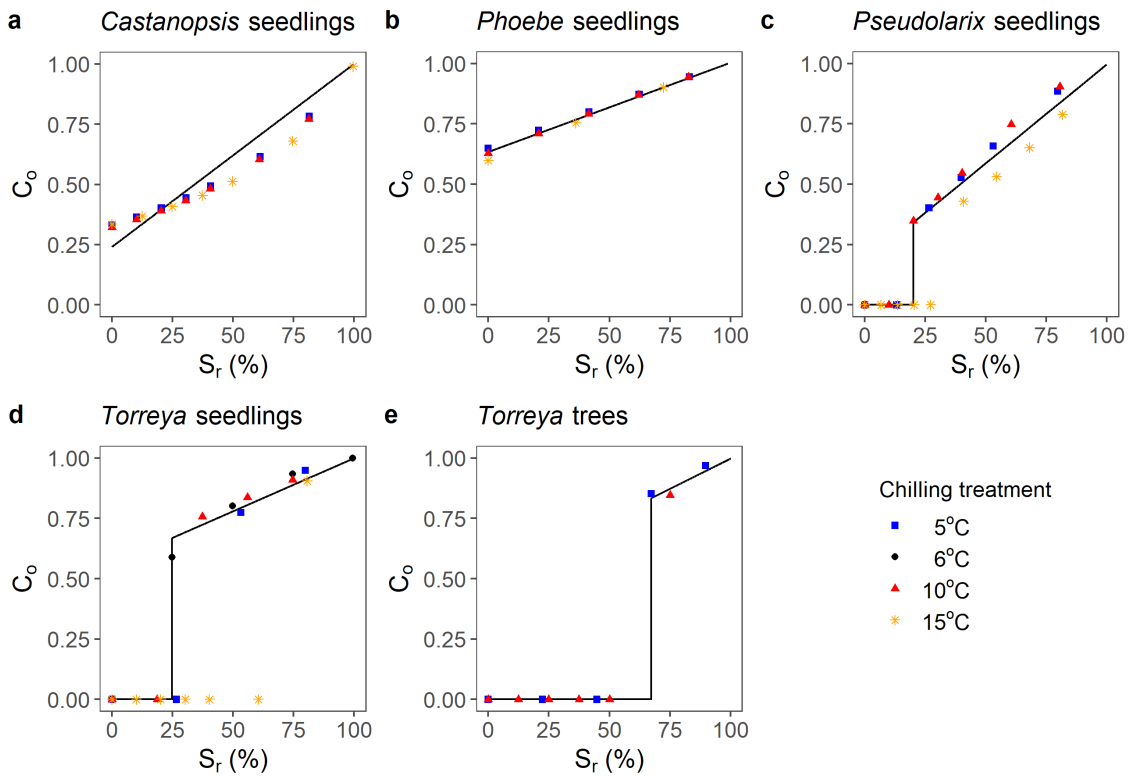


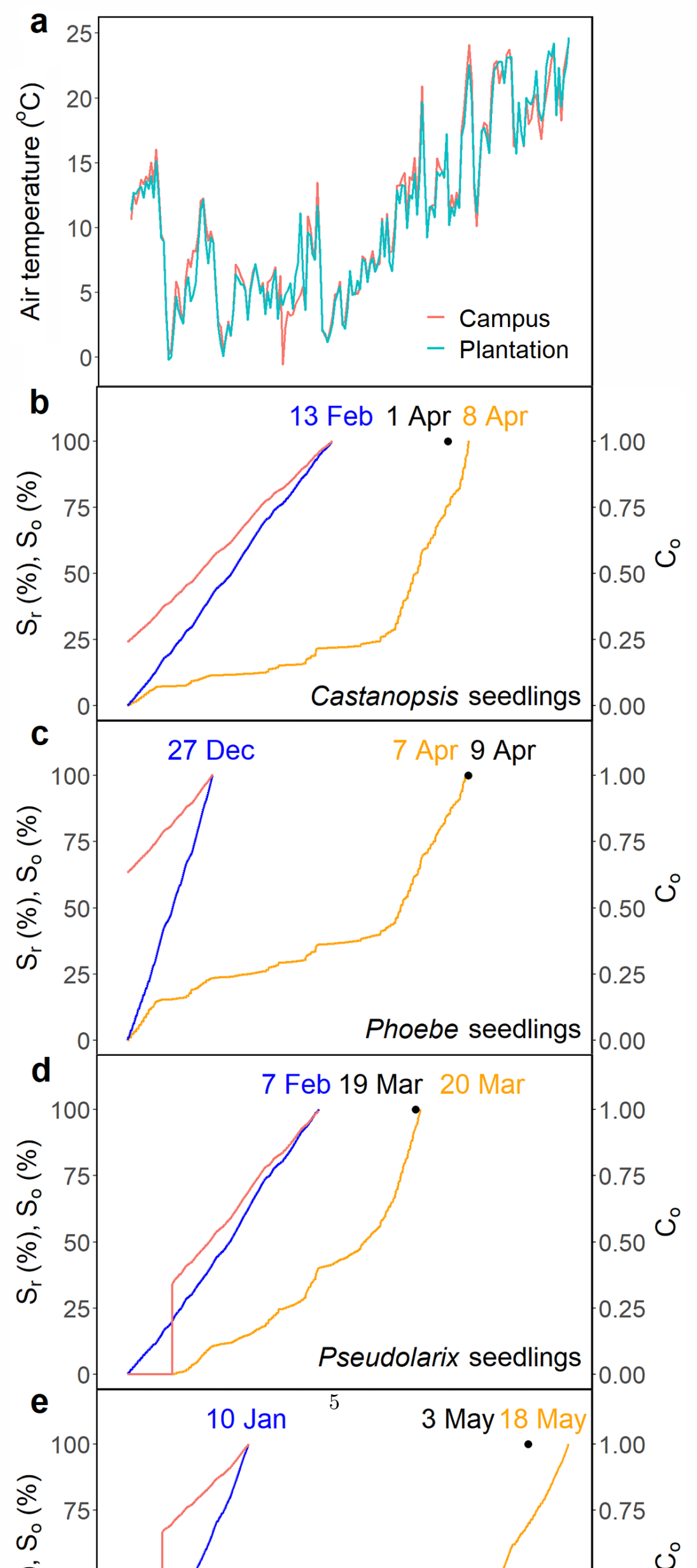



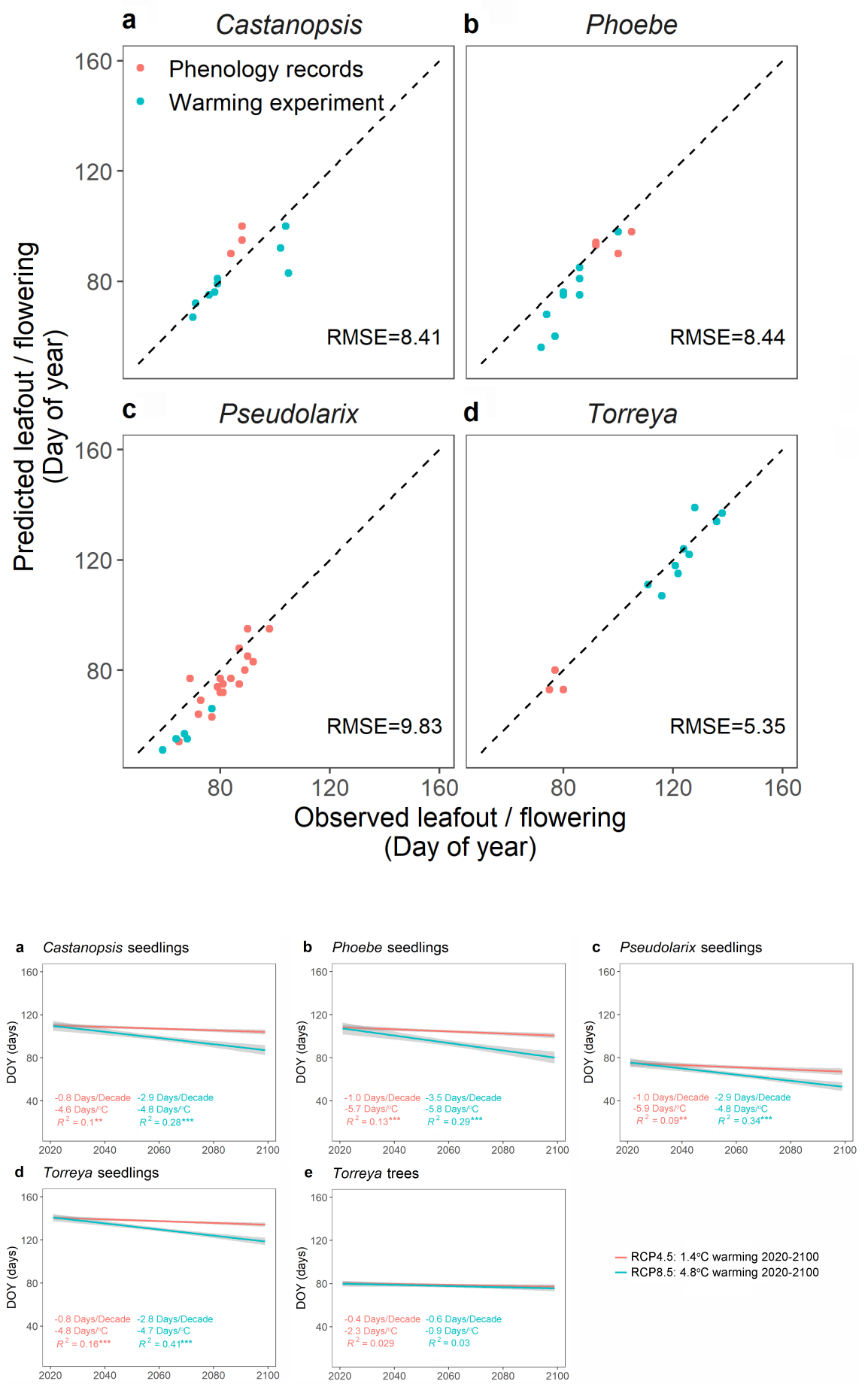